\section{Comparison of RAPD and AFLP Analysis in Some Maize (Zea mays L.) Lines and Hybrids}

\author{
Pál Pepó \\ University of Debrecen, Centre for Agricultural Sciences, \\ Faculty of Agricultural Sciences, \\ Department of Genetics and Plant Breeding, Debrecen \\ pepopal@agr.unideb.hu
}

\section{SUMMARY}

The use of molecular markers to enhance plant breeding efforts is being widely studied. DNA-based fingerprinting technologies (RAPD and AFLP) have proven useful in genetic similarity studies. We estimated different maize (Zea mays L.) inbred lines and hybrids originated from mutant ones based on their genetic differences.

We carried out RAPD analysis with different primers and the 707 (CCCAACACCC) and 792 (CAACCCACAC) primers with $50 \%$ similarities provided quite good DNA fragments. By applying the DNA based-AFLP technique, we had very dense DNA fingerprinting. We differentiated 15-32 polymorphic bands, the highest number of bands were found in P-T/H-CA (32). AFLP seems to be the more efficient method of comparing genetic similarities/differences among different genotypes.

Keywords: maize (Zea mays L.), RAPD technique, AFLP method, genetic similarity difference

\section{INTRODUCTION}

The use of molecular markers to enhance plant breeding efforts is being widely studied. Even though marker-assisted selection now plays a prominent role in the field of plant breeding, examples of successful, practical outcomes are rare. It is clear that DNA markers hold great promise, but realizing that promise remains elusive. Despite innovations like better marker systems and improved genetic mapping strategies, most marker associations are not sufficiently robust for successful marker-assisted selection. Molecular breeders must reassess their research programs so that DNA marker work leads to useful selection tools and valuable germplasm. As molecular breeders adapt more rigorous experimental guidelines and ambitious goals, they also need to integrate the growing body of knowledge from genomics and bioinformatics.

Molecular genetic maps are commonly constructed by analyzing the segregation of restriction fragment length polymorphisms (RFLPs) among the progeny of a sexual cross. Williams et al. (1990) described a new DNA polymorphism assay based on the amplification of random DNA segments with single primers of arbitrary nucleotide sequence. These polymorphisms, simply detected as DNA segments which amplify from one parent but not the other, are inherited in a Mendelian fashion and can be used to construct genetic maps in a variety of species. They suggested these polymorphisms be called RAPD markers after Random Amplified Polymorphic DNA.
Li et al. (2004) investigated the inheritance of shoot regeneration through shoot-tip meristem culture derived from maize seedling and the markers (RAPD and SSR) associated with this regeneration character were identified in maize inbreds and a crossing population. They were given information to determine the genetic mechanisms involved in the maize regeneration response related to shoot meristem culture pathway and to select high regenerable germplasm by using marker assisted selection. However Shieh and Thseng (2002) found that RAPD analysis in maize inbred lines was a useful tool among lines, but the Jaccard's similarity coefficients based on RAPD data cannot be used to precisely predict the $F_{1}$ hybrids yield performance and heterosis value.

Garcia et al. (2004) compared relative efficiencies of RAPD, RFLP, AFLP and SSR markers to find the most suitable one for maize diversity studies. The dominant markers (AFLP and RAPD) had small CV values indicating a skewed distribution while the codominant markers gave high $\mathrm{CV}$ values. The use of maximum values of genetic distance CVs within each sample size was efficient in determining the number of loci needed to obtain a maximum CV of $10 \%$. The number of RFLP and AFLP loci used was enough to give $\mathrm{CV}$ values of below 5\%, while the SSRs and RAPD loci gave higher $\mathrm{CV}$ values.

Lanza et al. (1997) found in investigating genetic diversity of maize inbred lines that RAPD can be used as a tool for determining the extent of genetic diversity among lines, for allocating genotypes into different groups, and also to aid in the choice of the superior crosses to be made among maize inbred lines, so reducting the number of crosses required under field evaluation. Szabó and Pepó (1998) found RAPD analysis as a useful tool for selecting herbicide tolerant/resistant maize lines and investigating inheritance of these characters with application of RAPD markers.

The genetic relationship among maize accessions consisting of landraces and improved varieties maintained by farmers were investigated using Random Amplified Polymorphic DNA (RAPD) (Carvalho et al., 2004). The analysis of the molecular data revealed that maize management adapted by small-scale farmers has contributed to the maintenance of genetic variability and since field isolation was a regular practice, variety identities had been preserved. These results were useful to establish and maintain a germplasm collection of landrace maize and design strategies that maximize the utility of maize genetic resources. 
Marsan et al. (1998) surveyed genetic divergence among inbred lines of maize using DNA markers (RFLP and AFLP) and assessed the relationship between genetic distance and hybrid performance in a diallel set of crosses between them. AFLPs detect polymorphisms more efficiently in comparison to RFLP, due to the larger number of loci assayed in a single PCR reaction. Genetic distances (GDs), calculated from RFLP and AFLP data, were greater among lines belonging to different heterotic groups compared to those calculated from lines of the same heterotic group.

Opposite to Marsan et al. (1998) findins, Wu and Dai (2000) concluded that AFLPs with high polymorphism can be used to investigate the relationship among maize inbreds, although they are of limited value for predicting the hybrid yield and yield heterosis of maize.

DNA-based fingerprinting technologies have proven useful in genetic similarity studies (Pejic et al., 1998). RFLP is still most commonly used in the estimation of genetic diversity in plant species, but the recently developed PCR-based marker techniques, RAPDs, AFLPs and SSRs are playing an increasingly important role in these investigations. AFLP technology can replace RFLP marker in genetic similarity studies.

Random primer polymerase chain reaction techniques are less time consuming and easier to carry out, but their reproducibility and resolution are not always satisfactory (Nagy et al., 2000; Nagy, 1999).

Lübberstedt et al. (2000) investigated the amount of variation for AFLP markers in maize inbred lines, examined the usefulness of AFLP markers for assigning inbred lines to heterotic groups, compared the genetic similarity (GS) based on AFLP markers. Correlation of GS estimates were substantially higher for AFLP markers than for RAPDs.

Chitto et al. (2000) conducted AFLP analysis on a series of maize inbred lines. Based on their results AFLPs appeared highly informative and constituted a valuable tool for assigning inbred lines to, and assaying genetic variability across, heterotic groups.

During the testing of various types of PCR primers it was found if a low number of primers exhibiting polymorphism were used, techniques based on the polymorphism of random sequence DNA regions (RAPD) gave a less accurate reflection of the actual relationship than methods based on the polymorphism of microsatellite regions (microsatellite-PCR, SSR) (Nagy et al., 2000).

Barbasa et al. (2003) investigated two sets of maize inbred lines with AFLP method. General results showed that the AFLP molecular marker is efficient in assigning maize lines to heterotic groups and that AFLP - based GD is suitable for predicting the maize single cross performance for intrapopulation crosses of broad-based populations.

\section{MATERIALS AND METHODS}

\section{Plant material}

Maize inbred lines originated from earlier mutation breeding program. These were derived from populations introduced from popular $\mathrm{F}_{1}$ hybrids. Identification, origin and information about their genotypes are described in Table 1.

Maize lines/hybrids applied for RAPD/AFLP analysis

\begin{tabular}{|c|c|c|c|}
\hline Lines hybrids & Genotypes pedigree & Type of irradiation & Dose [Gy] \\
\hline K13 (S1) & $\mathrm{F}_{1}(\mathrm{NK}-\mathrm{X} 14) \mathrm{M}_{2} 1 \mathrm{~B}-3$ & $\mathrm{Co}^{60}$-fn & $15-7,5$ \\
\hline K14 (S4) & $\mathrm{F}_{1}(\mathrm{Pi} 3978 \mathrm{SC}) \mathrm{M}_{3} 23 \mathrm{~B}-4$ & Fn & 5 \\
\hline K15 (S5) & $\mathrm{F}_{1}(\mathrm{Pi} 3764 \mathrm{MTC}) \mathrm{M}_{3} 54 / 2 \mathrm{~B}-4$ & Fn & 5 \\
\hline K16 (S6) & $\mathrm{F}_{1}(\mathrm{Pi} 3478) \mathrm{M}_{2} 82 / \mathrm{B} 2-2$ & Fn & 5 \\
\hline A2 (P14xP35) & $\mathrm{F}_{1}(\mathrm{Pi} 3950 \mathrm{MSC}) \mathrm{M}_{2} \times \mathrm{F}_{1}(\mathrm{Pi} 3780 \mathrm{MSC}) \mathrm{M}_{2}$ & $\mathrm{Co}^{60}$-fn & $20-5 / 12,5-7,5$ \\
\hline A10 (P62xP14) & $\mathrm{F}_{1}(\mathrm{Pi} 3901 \mathrm{SC}) \mathrm{M}_{3} \times \mathrm{F}_{1}(\mathrm{Pi} 3950 \mathrm{MSC}) \mathrm{M}_{2}$ & $\mathrm{Co}^{60}$-fn & $7,5 / 20-5$ \\
\hline
\end{tabular}

fn: fast neutron

All inbred lines were led to homozygosity by successive self-fertilizations.

Thirty seeds of each inbred line/hybrid were planted in greenhouse pots. Young leaves from at least 15 plants, from 6 to 8 weeks, were collected, freeze-dried ( $72 \mathrm{~h},-60^{\circ} \mathrm{C}, 05$ to $10 \mathrm{Hg}$ microns), grounded to powder using a mechanical mill and stored in a $-20^{\circ} \mathrm{C}$ freezer.

\section{DNA extraction and quantification}

Genomic DNA of the leaves was extracted following the method described by Hoisington et al. (1994). A total of $300 \mathrm{mg}$ of leaves, freeze-dried and grounded to power, was used together with CTAB
(100 mM Tris-pH 7.5, 700 mM NaCl, 50 mM EDTA $\mathrm{pH}$ 8.0), followed by two successive extractions with chloroform/isoamilic alcohol (24:1). The DNA of each sample was still submitted to a final extraction with phenol/chloroform and lunged with TE buffer (10 mM Tris pH. 8.0; 1 mM EDTA pH 8.0). The DNA obtained was examined regarding its quality and concentration in poliacrilamid gels.

\section{PCR reaction}

This method is based on the in vitro amplification of DNA with the help of specific or arbitrary primers and Taq polymerase. Starting from a very low amount of template DNA (in the nanogram range), 
millions of copies of one or more particular target DNA fragments are produced, which can be electrophoresed and visualized by staining or autoradiography. PCR is characterized by its high speed, selectivity and sensitivity. The selectivity of the reaction is determined by the choice of the primers. Primers are single-stranded pieces of DNA with sequence complementary to template sequences flanking the targeted region. For exponential amplification primers must anneal in opposite directions, so that their 3' ends face the target. Amplification is most efficient when the two promoter binding sites are not further apart than $4 \mathrm{~kb}$.

\section{RAPD method}

From the wide range of genetical mapping techniques we choosed RAPD (random amplified polymorphic DNA) analysis because of its simplicity. This methods based on PCR reactions and has several advantages in contrast with other mapping methods, such as RAPD analysis is quick to perform, the DNA does not need to be as pure as for other mapping techniques, there is no need for species specific genomic or cDNA derived probes, and radioactive materials are not involved.

From a technical point of view, this is the simplest PCR method using arbitrary primers. We extracted DNA samples from the leaves of maize plants being in 3-4 leaves stadium. Extraction was carried out by the Potassium Acetate Procedure. This strategy of plant DNA isolation was introduced by Dellaporta et al. Its key step relies on the simultaneous precipitation of proteins and polysaccharides by high concentration of potassium acetate in the presence of SDS.

PCR was performed in a volume of $20 \mu \mathrm{l}$ containing $50 \mathrm{mM} \mathrm{MgCl} 2,10 \mathrm{mM}$ dNTP mix, $15 \mu \mathrm{M}$ primer, Taq polymerase (5 unit/ $\mu \mathrm{l}$ ), $20 \mathrm{ng} / \mathrm{ml}$ DNA. Amplification was performed in Programmable Thermal Cycler. The thermal cycle used was: $94^{\circ} \mathrm{C}$ ( $2 \mathrm{~min}$ ) for initial strand separation, then 40 cycles at $37^{\circ} \mathrm{C}$ (15 sec) for annealing, $72^{\circ} \mathrm{C}$ (30 sec) for extension. Amplification products were analyzed by electrophoresis in 1,5\% agarose (Reanal) gels and were detected by staining with ethidium bromide.

\section{AFLP analysis}

AFLP analysis profiles were performed as described by Vos et al. (1995), using the „AFLP Analysis Kit”, following the patterns of the manufacturer. The genomic DNA (400 ng) of each inbred line was isolated and digested simultaneously at $37^{\circ} \mathrm{C}$, for two hours, by the EcoRI and MseI adapters, 0,4 mM ATP, $10 \mathrm{mM}$ Tris-HCl pH 7,5, 10 $\mathrm{mM}$ Mg-acetate, $50 \mathrm{mM} \mathrm{K}$-acetate and $1 \mu \mathrm{l}$ of DNA ligase and then diluted ten times in a TE buffer (EcoRI enzyme had been substituted by Pst1 enzyme). Next, $5 \mu \mathrm{l}$ of diluted DNA were amplified in a PTC $^{\mathrm{TM}}-100$ termocyclator (Programmable Thermal Controller) for 20 cycles $\left(94^{\circ} \mathrm{C}\right.$ for $1 \mathrm{~s}$, 65$56^{\circ} \mathrm{C}$ for $30 \mathrm{~s}, 72^{\circ} \mathrm{C}$ for $120 \mathrm{~s}$ in 9 cycles; $94^{\circ} \mathrm{C}$ for $1 \mathrm{~s}, 56^{\circ} \mathrm{C}$ for $30 \mathrm{~s}, 72^{\circ} \mathrm{C}$ for $120 \mathrm{~s}$ in 22 cycles), amplified product, 3,0 $\mu \mathrm{l}$ of this mixture for each inbred line was applied in a $6 \%$ denaturing polyacrylamide gel and submitted to electrophoresis for $50 \mathrm{~min}$ in $75-85 \mathrm{~W}$.

\section{RESULTS AND CONCLUSIONS}

For DNA multiplication we applied two maize inbred lines (A2 and A10), which DNA solution after extraction contained different amounts of genetic material. We used the PCR method for DNA multiplication and gelelectrophoresis to obtain the DNA pattern which is shown in Figure 1.

Figure 1: DNA pattern of two maize inbred lines (A2, A10)

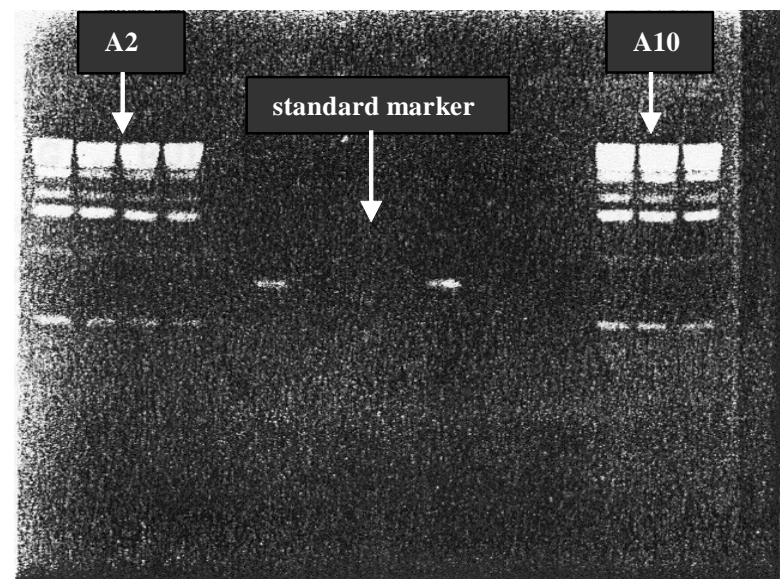

We can see discrete bands in both of the lines which differs from each other. Molecular weight can be compared to the $1 \mathrm{~kb}$ standard markers. However, in some cases, the bands are not so clear and the positions are not determined in an adequate way. These must be because of unsuitable PCR products, composite fragments and contaminants.

Applying the Potassium Acetate Procedure for DNA extraction, we slightly modified this method. We optimized the amount of plant material in 0,05 g. The use of much more plant material increases the amount of each contaminant, such as RNA, protein, or polysaccharides.

For RAPD analysis we had the following primers:

\section{CCCAACACCC \\ 715 CCACCACCCA \\ 746 GGGTGTTGGG \\ 764 CTCTCCTCCC \\ 768 TCCCTCCTCC \\ 774 GGTGTGTGGT \\ 789 GGAAGGGAGA \\ 792 CAACCCACAC \\ 796 AGAGGGAGGA}

We carried out RAPD analysis with all the primers mentioned above. Out of the 10 primers, numbers 707 and 792 provided quite good DNA fragments

$\begin{array}{ll} & \downarrow \\ 707 & \text { CCCAACACCC } \\ 792 & \text { CAACCCACAC }\end{array}$


Regarding the sequence of the primers, we found a $50 \%$ similarity to each other.

For AFLP analyses, we applied 7 primer combinations, which were the following: $\mathrm{P}-\mathrm{C} / \mathrm{M}-\mathrm{CA}$, $\mathrm{P}-\mathrm{T} / \mathrm{M}-\mathrm{CA}, \mathrm{P}-\mathrm{A} / \mathrm{M}-\mathrm{CT}, \mathrm{P}-\mathrm{C} / \mathrm{M}-\mathrm{CT}, \mathrm{P}-\mathrm{A} / \mathrm{M}-\mathrm{CC}, \mathrm{P}-$ $\mathrm{A} / \mathrm{M}-\mathrm{CA}$. We had very dense DNA fingerprinting using the PCR-based AFLP techniques illustrated in Figure 2.

We estimated that the number of polymorph bands totalled 145, which means 21 ones in average for a particular primer combinations. The highest number of bands were found in P-T/M-CA (32) and furthermore we found the following polymorphic bands in the following primers: P-C/M-CA (30), PC/M-CT (26), P-A/M-CC (24), P-A/M-CT (21), PA/M-CG (18), P-A/M-CA (15).

We can conclude that the AFLP markers provide a large number of polymorphic bands. Therefore, by applying a few primer combinations, we can detect the genetic variation. Furthermore we can easily demonstrate the genetic distance using this molecular method. However, as we illustrated the RAPD technique provided more narrow genetic polymorphisms in contrast with AFLP, where we can differentiate 15-32 polymorphic bands only in one PCR reaction. AFLP seems to be more efficient technique for comparing genetic similarities/differences among different genotypes.

Acknowledgements - The author wish to thank British-Hungarian Scientific Cooperation Fund (Tét) for the financial support and Cereal Research Institute, Szeged for realisation of this research.
Figure 2: DNA band pattern of maize inbred lines with application of different primers in AFLP technique

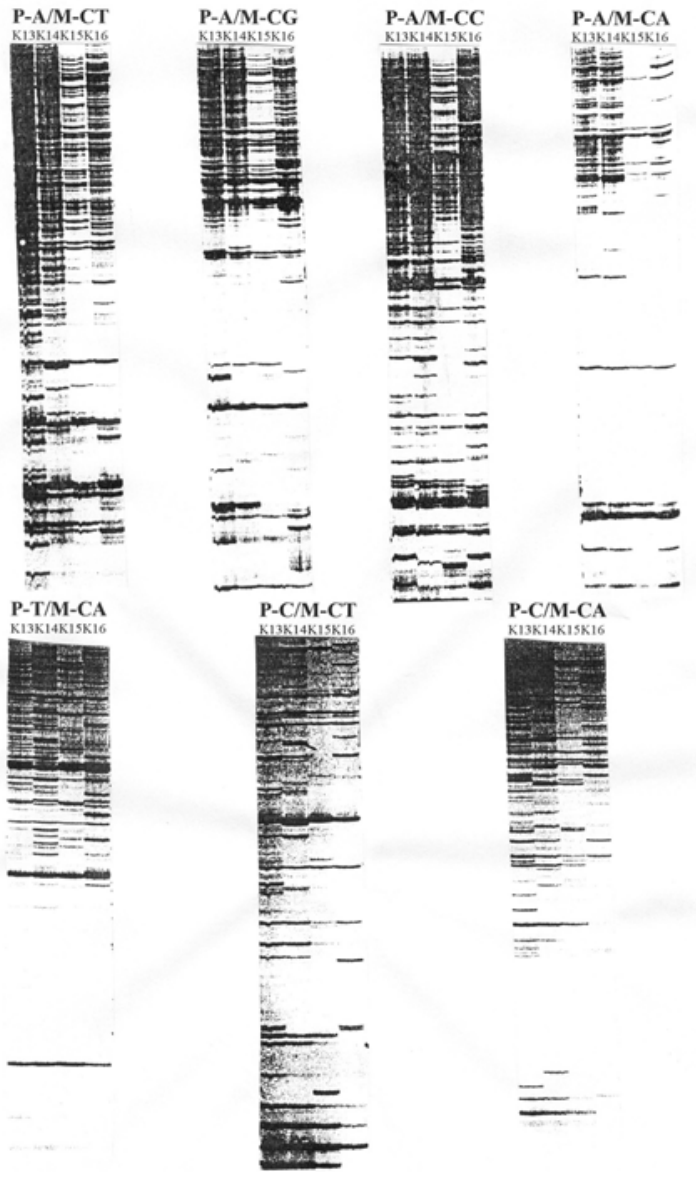

\section{REFERENCES}

Barbasa, A. M. M.-Geraldi, I. O.-Benehimol, L. L.-Garcia, A. A. F.-Souza, C. L.-Souza, A. P. (2003): Relationship of intra- and interpopulation tropical maize single cross hybrid performance anda genetic distances (GD) computed from AFLP and SSR markers. Euphytica, 130. 1. 87-99.

Carvalho, V. P.-Ruas, C. F.-Ferreira, J. M.-Moreira, R. M. P.Ruas, P. M. (2004): Genetic diversity among maize (Zea mays L.) landraces assessed by RAPD markers. Genetics and Molecular Biology, 27. 2. 228-236.

Chitto, A.-Bertolini, M.-Hartings, H.-Verderio, A.-Motto, M. (2000): AFLP-based genetic relationships among maize inbreds lines selected in a climatically temperate location. Mayidica, 45. 3. 257-266.

Dellaporte, S. L.-Wood, J.-Hicks, J. B. (1983): A plant DNA minipreparation: version II. Plant Mol. Biol. Rep., 1. 19-21.

Garcia, A. A. F.-Benchimol, L. L.-Barbosa, A. M. M.-Geraldi, I. O.-Souza, C. L.-de Souza, A. P. (2004): Comparison of RAPD, RFLP, AFLP and SSR markers for diversity studies in tropical maize inbred lines. Genetics and Molecular Biology, 27. 4. 579-588.

Hoisington, D.-Khairralloh, M.-González-de-León, D. (1994): Laboratory protocols: CIMMYT applied molecular genetics laboratory, $2^{\text {nd }}$ edn. - CIMMYT, Mexico

Lanza, L. L. B.-de Souza Jr C. L.-Ottoboni, L. M. M.-Vieira, M. L. C.-de Sopuza, A. P. (1997): Genetic distance of inbred lines and prediction of maize single-cross performance using RAPD markers. Theoretical and Applied Genetics, 94. 8. 1023-1030.
Li, W.-Sun, G.-Liu, J.-Masilamany, P.-Taylor, J. H.-Jan, W.Kasha, K. J.-Pauls, K. P. (2004): Inheritance of plant regeneration from maize (Zea mays L.) shoot meristem cultures derived from germinated seeds and the identification of associated RAPD and SSR markers. Theoretical and Applied Genetics, 108. 4. 681-687.

Lübberstedt, T.-Melchinger, A. E.-Dussle, C.-Vuylsteke, M.Kuiper, M. (2000): Relationships among early European maize inbreds: IV. Genetic diversity revealed with AFLP markers and comparison with RFLP, RAPD and pedigree data. Crop Science, 40. 3. 783-791.

Marsan, P. A.-Castiglioni, P.-Fusari, F.-Kuiper, M.-Motto, M. (1998): Genetic diversity and its relationship to hybrid performance in maize as revealed by RFLP and AFLP markers. Theoretical and Applied Geneties, 96. 2. 219-227.

Nagy, E.-Gyulai, G.-Marton, L. Cs. (2000): Characterization of maize lines by using genetic markers. Crop Production, 48. 6 . 587-599.

Nagy, I. (1999): Improved PCR-based techniques for polymorphism investigations. Crop Production, 48. 4. 421435.

Pejic, I.-Ajmone-Marsan, P.-Morgante, M.-Kozumplick, V.Castiglioni, P.-Taramino, G.-Motto, M. (1998): Comparative analysis of genetic similarity among maize inbred lines detected by RFLPs, RAPDs, SSRs and AFLPs. Theoretical and Applied Genetics, 97. 8. 1248-1255. 
Shieh, G. J.-Thseng, F. S. (2002): Genetic diversity of Tainanwhite maize inbred lines and prediction of single cross hybrid performance using RAPD markers. Euphytica, 124. 3. 307313.

Szabó, E.-Pepó, Pál (1998): Inheritance of RAPD markers in maize (Zea Mays L.). IV. Plant Breeding Proceedings, 122.

Vos, P.-Hogers, R.-Bleeker, M. (1995): AFLP: A new technique for DNA fingerprint. Nucleic Acids Res., 23. 4407-4414.
Williams, J. G.-Kubelik, A. R.-Livak, K. J.-Rafalski, J. A.-Tingey, S. V. (1990): DNA polymorphisms amplified by arbitrary primers are useful as genetic markers. Nucleic Acids Research, 18. 22. 6531-6535.

Wu, M. S.-Dai, J. R. (2000): Use of AFLP marker to predict the hybrid yield and yield heterosis in maize. Acta Botanica Sinica, 42. 6. 600-604. 